\title{
SEMIÓTICA DE LA CULTURA ESPAÑOLA (II): EL LÉXICO
}

\author{
Francisco Abad
}

(UNED, Madrid)

\section{LENGUA Y CULTURA}

Hace ya bastantes años subrayaba Gerhard Rohlfs la importancia del vocabulario en los estudios lingüísticos; además de constituir uno de los motivos de su oposición a Vossler, trataba de manifestar el relieve de tales análisis en la consideración de las relaciones entre cultura y lengua. Rohlfs escribía así a la letra: «Siempre me ha admirado por qué por ejemplo los elementos léxicos del idioma, desempeñan un papel tan poco importante en los trabajos de Vossler. Y sin embargo la historia de las palabras nos ofrece mejor que cualquiera otra materia, la posibilidad de practicar investigaciones científicas basadas en cimientos culturales» (1979:26).

Estamos pues ante un hecho de semiótica de la cultura o «práctica social significante» al decir de Greimas: el léxico se constituye -como también se ha dicho tradicionalmente- en un espejo de la vida. Espejo de la vida (creemos nosotros) tanto material como intelectual y 
espiritual; en esto la postura de Rohlfs resulta aún un tanto unilateral, puesto que proclamaba: «Es claro que las relaciones entre lengua y cultura son más evidentes y visibles en el dominio de la cultura material, en tanto se hacen más vagas e indiscriminadas conforme nos acercamos a la cultura espiritual» (1979:26-27n.).

A fines del primer tercio de este siglo a los dialectólogos les parecía que la cultura material resulta un fundamento más empírico y concreto para el estudio del vocabulario como espejo de la vida; transcurridos los años sabemos y proclamamos que asimismo el mundo de las aspiraciones colectivas, del pensamiento teórico, de la política, etc., está reflejado en la lengua.

Al hilo de las discusiones de Gerhard Rohlfs, su anotador español Manuel Alvar incluye sucesivos ejemplos hispánicos. Alvar toma datos de Américo Castro y aborda «el reflejo que sobre el español tuvo el desarrollo comercial de los Países Bajos y de la Francia septentrional»: nuestros aranceles de aduanas consignan la importación de tejidos como el popelín (de Poperinghe), el ranzal (de Reims), la holanda, el gante, el ras (de Arras), la frisa,... También al margen de los tejidos el desarrollo mercantil de Flandes ha dejado su huella en designaciones como valona 'collarón del yugo', galdrés 'capote' (de Güeldres), bramante, balduque 'cordel' y belduque 'cuchillo' (de Bois-le-Duc), holandesa 'hoja de papel más pequeña que la española', etc. (Rohlfs, 1979: 32-33).

En Andalucía - se trata de otro ejemplo de léxico y cultura material-, el término corcho para designar la 'colmena' «está favorecido por la explotación de los alcornoques: todas las áreas occidentales... donde el término subsiste producen hoy corcho»; en todo caso debió ser designación de la lengua común o traída por repobladores, pues aparece en zonas que no producen corcho. En Calabria hay colmenas construidas con cortezas dobladas, y asimismo en Cataluña se dan colmenas hechas con corteza de árbol (Rohlfs, 1979: 62-63).

Pero ya queda dicho que no sólo la cultura material, las creencias folclóricas, etc., se reflejan en el léxico. Rafael Lapesa escribía a mitad de los años sesenta cómo el estudioso puede «allegar datos sobre palabras... y a continuación reconstruir los complejos de... pensamiento en que tales formas de lenguaje se insertaban orgánicamente» (19661967:189); de igual manera se manifestó en 1968 al decir que cabe «acotar un sector del léxico vigente en un período histórico dado, precisar las afinidades significativas entre las palabras que lo constituyen, 
las diferencias... que oponen unas a otras,... y diseñar la concepción del mundo a que correpsonde[n]» (apud Seoane, 1968:15).

En efecto no estamos ya en los tiempos en que los dialectólogos romanistas se interesaban sólo por la cultura dialectal rural y por la cultura folclórica tradicional; la lingüística se hace cargo asimismo de creencias, ideas, realidades, etc., del mundo de lo histórico y lo político. Precisamente la indagación hecha por María Cruz Seoane fue presentada por Lapesa en tanto «un tipo de investigación llamado a prestar inestimable auxilio a la Historia de las ideas y a la Historia general», clase de investigación que esta profesora «inaugura[ba] en la lingüística española» (Ibid.)

El trabajo de Seoane más cuatro artículos del propio Lapesa tuvieron su nacimiento en realidad en el «Seminario de Estudios de Humanidades» que promovió Julián Marías desde 1960 en la Sociedad de Estudios y Publicaciones de Madrid; ese Seminario se proponía esclarecer la realidad de la España estrictamente contemporánea, según indicaba Marías, y para ello se remontó hasta 1750, pues «la España de nuestro tiempo presenta caracteres que se constituyen casi sin excepción desde medidos del siglo XVIII hasta el final de la época romántica»; entonces surgen «los rasgos que constituyen a la vez nuestros recursos y nuestros problemas» (1966:294).

Ciertamente la historiografía estima que es hacia 1750/1765 cuando empezamos a entrar en el mundo nuevo de lo contemporáneo, y el período revolucionario más decisivo llega hasta mitad del Ochocientos. Julián Marías manifiesta con expresión feliz cómo entonces se ges$\tan$ «nuestros problemas» $y$ «nuestros recursos»; Miguel Artola también ha venido a decir lo mismo en sus trabajos, y acaso su planteamiento ha estimulado el de Marías.

Por su lado José Antonio Maravall se ha hecho cargo de las presentes cuestiones, y en su libro Teoría del saber histórico - una de las obras de importancia de las ciencias humanas en España- se refiere al desarrollo de los estudios léxico-semánticos y a la aproximación que cumplen «al campo de la historia del pensamiento»; lo semántico y léxico (proclama) «refleja la mentalidad de cada época». Maravall piensa en el análisis de las estructuras semánticas y de léxico, y describe así lo que ello alcanza al estado actual del saber histórico: «La historificación del lenguaje en la ciencia de hoy es una tendencia manifiesta, y esa su condición histórica viene entendida en un sentido estructural. Por eso [los actuales estudios semánticos] se construyen... 
según conjuntos estructurados históricos: Revolución francesa, romanticismo», etc. (1967: 190-191).

Las unidades verdaderas del acontecer histórico se hallan por tanto en los conjuntos temporales y estructurales («siglos XIV y XV», «Renacimiento», «Barroco»,...), y la mentalidad de cada una de esas épocas se refleja en lo semántico y el vocabulario, el cual a su vez se encuentra interiormente estructurado como lo está todo el lenguaje.

El análisis léxico y semántico constituye pues un capítulo de la ciencia historiográfica. Creemos que no nos engaña la memoria si decimos que José María Jover habla en sus clases de la existencia en los momentos del pasado de un «vocabulario de situación» específico; ese vocabulario debe inventariarlo y analizarlo en su estructura el filólogo. Más ampliamente Jover reclama el análisis de contenido de los textos: por ejemplo (es ejemplo suyo y de sus clases), Galdós nos ha sabido transmitir climas psicológicos colectivos que en vano buscaremos en otras fuentes.

La función referencial del lenguaje hace que una parte del análisis del pasado pueda llevarse a cabo mediante los estudios léxicos; el léxico de la literatura es distinto en lo que tiene de artístico, pues en efecto el vocabulario artístico llega a serlo mediante la ruptura o la reordenación de muchos rasgos de la lengua ordinaria.

\section{EL VOCABLO «ESPAÑOL»}

Como es sabido a la palabra español se ha referido varias veces Américo Castro. A la altura de 1954 decía simplemente don Américo:

Pienso que el adjetivo español no puede aplicarse con rigor a quienes vivieron en la Península Ibérica con anterioridad a la invasión musulmana. Si llamamos españoles a visigodos, romanos, iberos, etc., entonces hay que denominar de otro modo a las gentes en cuyas vidas se articula lo acaecido y creado (o aniquilado) en aquella Península desde el siglo $\mathrm{X}$ hasta hoy. Al afirmar que el busto de la Dama de Elche o las Etimologías de San Isidoro son obras españolas, lo que se quiere decir es que ambas fueron obra de personas que habitaban en lo que hoy llamamos España (1954:54).

Nuestro autor se muestra preocupado por la semántica del vocablo, 
por la realidad histórico-humana referida en él; cinco años más tarde sin embargo, al prologar una reunión de artículos suyos, hace referencia a que - de acuerdo con Aebischer- el nombre «español» se originó en Provenza. «Hispania (concluye) era el nombre de una provincia romana;... España y español designan otro modo de realidad humana» (1959:IX).

Don Américo ha pasado de no atender una investigación de Paul Aebischer publicada en 1948 a atenderla; y a dar gran relieve al hecho de que «español» es vocablo provenzal. Él no lo dice, pero parece claro que quien le puso en la pista del trabajo de Aebischer fue José Antonio Maravall con su libro El concepto de España en la Edad Media, aparecido por vez primera en 1954; antes de esta obra no hemos encontrado que Américo Castro mencione a Paul Aebischer, y por contra sí lo hace después, desde luego ya en 1959 (como queda visto).

Don Américo y Maravall mantuvieron una sincera estima personal mutua, pero cada uno estuvo muy atento a las publicaciones del otro y - sin mención explícita - cada uno opuso unas razones científicas al otro; por nuestra parte estamos completamente persuadidos de que fue el libro mencionado de El concepto de España... el que llamó la atención de Américo Castro sobre el trabajo de Aebischer publicado en Barcelona por el CSIC. No debe extrañar que a un don Américo exiliado y distante del régimen de Franco le hubiese quedado desapercibida una publicación hecha en el temprano 1948 por instancia oficial de tanto relieve como era entonces el CSIC; además no se trataba sólo de una instancia oficial, sino del organismo con el que Franco pretendía sustituir el Centro de Estudios Históricos en el que había estado de joven don Américo, y a cuyo espíritu se sentía vinculado. Tampoco se olvide que a esta altura de 1948 sus amigos queridos Menéndez Pidal y Rafael Lapesa estaban oficialmente mal vistos: a Américo Castro es verosímil que le hubiese pasado desapercibido el libro de Aebischer en que se demostraba cómo español es un provenzalismo.

Pero según decimos la obra de José Antonio Maravall de 1954 sí se hacía cargo del lingüista suizo; Maravall exponía cómo «queda una cosa firmemente establecida: el testimonio de una constante conciencia de la singularidad del grupo humano que se encuentra al otro lado de los Pirineos, manifestada en tantos y tan tempranos ejemplos del uso del nombre español en el Mediodía lenguadociano» (1981:483). 
El dato léxico puesto de relieve por Paul Aebischer fue muy valorado por don Américo, quien lo insertó en el conjunto de su interpretación historiográfica: si en los reinos norteños -venía a decir- lo religioso resultaba el principal común denominador, no hacía falta ninguna denominación secular que fuese común, y así se aceptó un nombre provenzal.

Nuestro autor sin embargo habla de un espesor de veinte años en que el hallazgo de Aebischer se ha visto silenciado: los que van de 1948 al 1970 en que él publica su pequeño libro «Español», palabra extranjera; el dato objetivo es sin embargo que tal silencio no se había producido, pues al menos lo tenía roto José Antonio Maravall. Acaso don Américo - lo decimos con total respeto- cayó en la tentación infantil que a veces acosa al estudioso de no darse por enterado de algo que ya ha visto un colega. Por extenso Américo Castro escribía en 1970:

\begin{abstract}
Es de todos modos sorprendente el mutismo - de veinte años de espesor-, ante la incontrovertible demostración de Aebischer de ser provenzal el nombre de los españoles [...] Los habitantes de la Península no supieron o no pudieron darse un nombre que a todos los abarcara, y a la postre aceptaron uno venido de fuera... El conjunto de quienes poblaban el norte de la Península y peleaban contra los moros, tenían como nombre común desde el siglo IX el de cristianos y nada más... Aceptado el hecho de que en los reinos cristianos... lo religioso... predominaba sobre lo secular, es comprensible que no se sintiera la necesidad de aunar en una denominación secular a gallegos, leoneses, castellanos, navarros, aragoneses y catalanes (1973:37-39).
\end{abstract}

Tenemos pues que el provenzalismo del vocablo español ha sido probado por un estudioso suizo, y que ese hecho léxico don Américo lo acoge en cuanto concuerda con su idea de que los españoles no se constituyeron sino como grupo humano posterior a la invasión musulmana y en torno a la creencia cristiana.

Pocos ejemplos resultan tan representativos como el que nos ocupa: la investigación léxica tiene un alcance historiográfico. Puede coincidirse o no con Américo Castro, pero se trata de una muestra — según decimos- de la repercusión interpretativa que puede alcanzar el estudio del vocabulario. No estamos sólo ya ante la ilustración de la cultura material de una pequeña comunidad, sino ante cuestiones centrales que se ha planteado la historiografía.

Don Américo considera coherente que los cristianos del Norte peninsular no poseyesen un nombre común (tal nombre hubo en definitiva que importarlo), y el hecho de que en efecto esos cristianos 
constituyesen un grupo formado a partir de la invasión musulmana y articulado por su propia creencia religiosa.

A su vez Rafael Lapesa glosó el dato léxico estudiado e interpretado por Aebischer y por Américo Castro. Con gran pulcritud intelectual Lapesa ha expuesto la cuestión: «En ciertos dominios de Occitania... español se registra desde fines del siglo XI ya como nombre propio, ya como nombre étnico, y desde allí se irradia... El nombre... entró en la Península... en el siglo XII [...] Cuando a partir del siglo XI se rompió [el aislamiento de los cristianos hispanos] respecto de Europa, al encontrarse con cristianos de otros países, aceptaron el dictado de españoles» (apud Américo Castro, 1973:13-15).

Este ejemplo de la lexicología románica constituye una muestra - según queda visto- de los estudios de lengua y cultura aplicados al dominio de lo histórico y de las actitudes mentales.

\section{SOBRE EL LÉXICO ESPAÑOL «MODERNO»}

Lapesa fue autor en 1966-1967 (como ya está visto) de un bello artículo en torno al lenguaje de la Ilustración. Se refiere así por ejemplo a Feijoo y advierte su actitud de falta de escrúpulos ante el neologismo conveniente, ya procediese del latín o del francés; se le censuraron al benedictino en el momento, pero estuvieron en el Diccionario de Autoridades, los vocablos circunscripto, condimento, filamento, funámbulo, indulgente, intersticio, luctuoso, noción, solercia y turgencia. Asimismo los contemporáneos le censuraron contrincante, inelectuble, ingurgitar, intumescencia, resorte o undulación, pero Lapesa (que recoge estos testimonios de investigadores anteriores) subraya cómo tales palabras han ido entrando en los Diccionarios académicos; nunca han entrado sin embargo en el léxico oficial las palabras feijoonianas exprobar, maturación, musicante, rebocar, o turbillón (1966-1967: 191192).

En Macanaz, Campomanes y Jovellanos encuentra don Rafael que «para los hombres del siglo XVIII valía [el vocablo felicidad] lo que para nosotros bienestar» (1966-1967:204), y en efecto en las últimas ediciones de la Historia de la lengua española nota Lapesa este sentido dieciochesco de la felicidad en tanto 'bienestar de los pueblos'. 
La palabra industria en la acepción de operación en torno a los productos naturales la señala Corominas «ya en Moratín», pero no era nueva en tiempos de este escritor. José Antonio Maravall acepta un testimonio de 1576 (1991:148), y otros de la centuria siguiente; ocurrirá en fin de esta forma que en Campomanes «ya la palabra tiene..., como en cuantos de sus contemporáneos escriben de economía, la acepción nueva» (1991:151).

A su vez a lo que dice Corominas de la palabra fábrica debe añadirse - según estas indagaciones de Maravall—, que «lo ordinario desde el siglo XVIII, con importantes anticipaciones en los economistas del XVII, es llamar a los establecimientos transformadores de mercancías, y lugares e inmuebles en que están instalados, fábricas» (Ibid.).

La lengua española no se acaba en el Setecientos, y así el propio Rafael Lapesa ha hablado ya dos veces al menos del léxico castellano del siglo XX: la primera en el escrito «La lengua desde hace cuarenta años» (1963).

\section{CONCLUSIONES}

1. Hacia los años treinta de este siglo proclama Gerhard Rohlfs la importancia del estudio de los elementos léxicos que constituyen el idioma.

2. Rohlfs pide además el análisis de las relaciones entre la lengua y la cultura, cultura entendida -sobre todo- en el ámbito de lo material y folclórico.

3. El paso de los años ha mostrado sin embargo cómo pueden y deben estudiarse las relaciones entre lenguaje y cultura espiritual. Por ejemplo Rafael Lapesa señaló en su día que el léxico vigente en un momento histórico dado remite a complejos de pensamiento vigentes.

4. José Antonio Maravall ha notado por igual que los estudios léxicos acaban formando parte de la Historia del pensamiento, ya que están referidos a la historia de las mentalidades, etc.

5. En lo que tiene de artístico el lenguaje literario no es propiamente referencial, sino que está construido a partir de rupturas y reorganizaciones de los rasgos del sistema. 
6. Américo Castro acoge con gran énfasis el dato del provenzalismo de la palabra español, pues ello testimonia - según él- la falta de conciencia laica del grupo de los reconquistadores del Norte peninsular, unidos sólo antes que nada por su común espíritu religioso cristiano.

7. Autores como Rafael Lapesa o José Antonio Maravall han llevado a cabo indagaciones léxicas sobre la lengua de estos últimos siglos. Así debe hacerse, pues el idioma menos conocido es el que va de hacia 1760 hasta nuestros días.

\section{Referencias bibliográficas}

CAstro, A. (1954). La realidad histórica de España. México: Porrúa.

- (1959). Origen, ser y existir de los españoles. Madrid: Taurus.

- (1973). Sobre el nombre y el quién de los españoles. Madrid: Taurus.

LAPESA, R. (1966-1967). «Ideas y palabras: del vocabulario de la Ilustración al de los primeros liberales». Asclepio XVIII-XIX, 189-218.

Maravall, J.A. (1967). Teoria del saber histórico. Madrid: Revista de Occidente. Tercera edición.

- (1981). El concepto de España en la Edad Media. Madrid: Centro de Estudios Constitucionales. 3. ${ }^{\mathrm{a}}$ ed.

- (1991). Estudios de Historia del pensamiento español. Siglo XVIII. Madrid: Mondadori.

MARÍAS, J., (1966). Obras. VII. Madrid: Revista de Occidente.

RoHLFS, G. (1979). Estudios sobre el léxico románico. Madrid: Gredos.

SEOANE, M.C. (1968). El primer lenguaje constitucional español. Madrid: Moneda y Crédito. 